\title{
Correction to: Complement in the pathogenesis of Alzheimer's disease
}

\section{B. Paul Morgan ${ }^{1}$}

Published online: 21 September 2018

(C) The Author(s) 2018

\section{Correction to: Semin Immunopathol (2018) 40:113-124 https://doi.org/10.1007/s00281-017-0662-9}

The presentation of Fig. 2 was incorrect.

The correct version of Fig. 2 is given below.

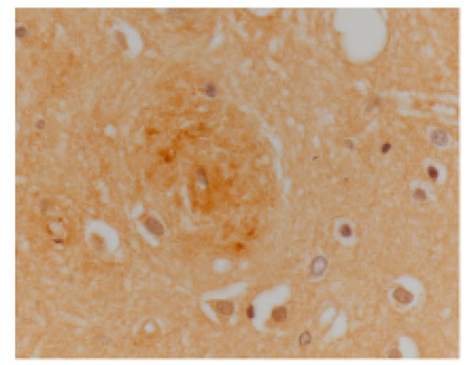

C1q staining in $A D$ brain

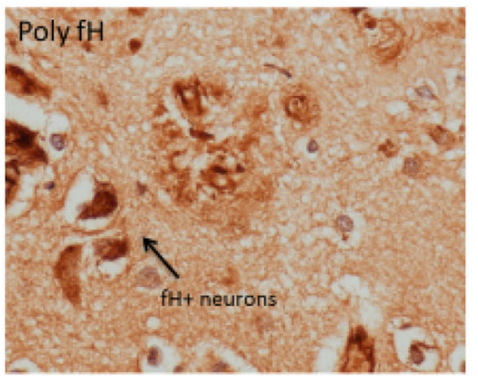

$\mathrm{CFH}$ on plaques and neurones

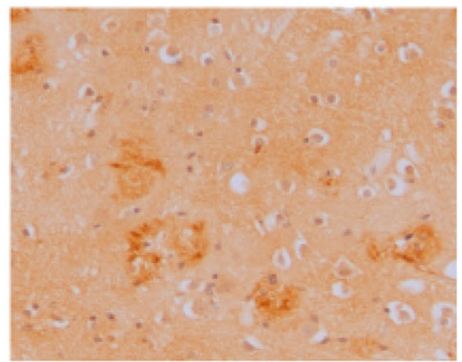

Low power MAC staining in $A D$ brain

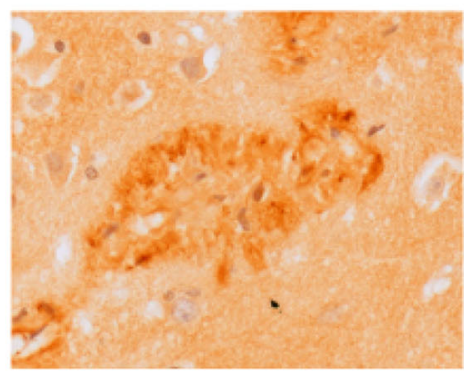

High power MAC staining of plaque

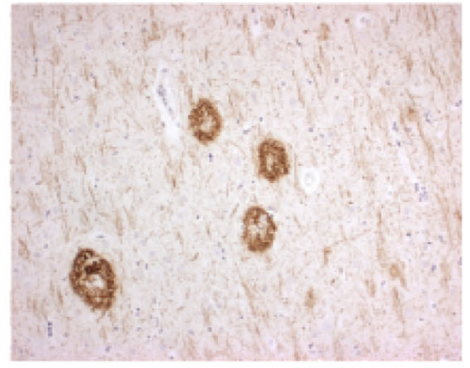

anti-Human $A \beta 40$ stained plaques

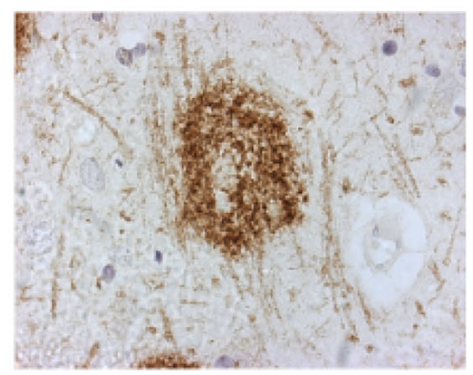

High power $A \beta 40$ stained plaque

Fig. 2 Complement components and activation products in the AD brain. Examples of AD brain sections stained with different complement antibodies: plaques stain strongly for $\mathrm{C} 1 \mathrm{q}, \mathrm{MAC}$ and $\mathrm{CFH}$. Neurons are also strongly positive for $\mathrm{CFH}$. A 340 staining of plaques is shown as a control

The online version of the original article can be found at https://doi.org/ 10.1007/s00281-017-0662-9

B. Paul Morgan

morganbp@cardiff.ac.uk

1 Systems Immunity Research Institute and Dementia Research Institute Cardiff, School of Medicine, Cardiff University, Cardiff CF14 4XN, UK
Open Access This article is distributed under the terms of the Creative Commons Attribution 4.0 International License (http://creativecommons.org/licenses/by/4.0/), which permits unrestricted use, distribution, and reproduction in any medium, provided you give appropriate credit to the original author(s) and the source, provide a link to the Creative Commons license, and indicate if changes were made. 